$\mathrm{C}_{6}-\mathrm{C}_{10}$-dicarboxylic acid glutaric aciduria glutaryl-CoA dehydrogenase deficiency ketosis

lactic acidosis

short-chain monocarboxylic acids

\title{
Ketotic Episodes in Glutaryl-CoA Dehydrogenase Deficiency (Glutaric Aciduria)
}

\author{
NIELS GREGERSEN AND NIELS JACOB BRANDT \\ Research Laboratory for Metabolic Disorders, University Department of Clinical Chemistry, Aarhus \\ Kommunehospital, Aarhus, and Section of Clinical Genetics, University Department of Paediatrics, Obstetrics, and \\ Gynaecology, Rigshospitalet, Copenhagen, Denmark
}

\begin{abstract}
Summary
A 7-yr-old boy with glutaryl-CoA dehydrogenase deficiency (glutaric aciduria), presenting periodic episodes of lethargy and ketosis, was studied during two such episodes. The urinary excretions of glutaric and 3-OH-glutaric acids were 3100-7900 and 460-660 $\mu \mathrm{g} / \mathrm{mg}$ creatinine, respectively, during these episodes. Urine samples collected before and after the attacks contained 100-5300 and 230-370 $\mu \mathrm{g} / \mathrm{mg}$ creatinine of glutaric acid and 3-OH-glutaric acids, respectively. During the episodes, glutaconic acid excretion rose from 14-89 to $93-630 \mu \mathrm{g} / \mathrm{mg}$ creatinine. Adipic acid and suberic acid excretions were increased from 17-100 and 2-13 to 74-224 and 16-32 $\mu \mathrm{g} / \mathrm{mg}$ creatinine, respectively. The excretions of conjugates of propionic, isobutyric, 2-Me-butyric, and isovaleric acids, outside and during the attacks, respectively, were: propionic acid, 7-13 and 5-19 $\mu \mathrm{g} / \mathrm{mg}$ creatinine isobutyric acid, 1-7 and 3$15 \mu \mathrm{g} / \mathrm{mg}$ creatinine; 2-Me-butyric acid, $2-9$ and $4-34 \mu \mathrm{g} / \mathrm{mg}$ creatinine; isovaleric acid, 0-6 and 3-11 $\mu \mathrm{g} / \mathrm{mg}$ creatinine. The excretion of total 2-oxo-acids was increased from 0-12 to 29-75 $\mu \mathrm{g} / \mathrm{mg}$ creatinine during the episodes. It is argued that one or more compounds, accumulated as a result of the primary glutarylCoA dehydrogenase deficiency, inhibit the oxidation of the branched-chain amino acids and the fatty acids. During excessive catabolism of amino acids and fatty acids this inhibition results in accumulation of metabolites that are excreted in the urine as conjugates and $\mathrm{C}_{6}-\mathrm{C}_{10}$-dicarboxylic acids, respectively. Short- and medium-chain monocarboxylic acids are known to affect energy metabolism, and it is, therefore, argued that the short-chain monocarboxylic acids, shown to be accumulated in the patient during the ketotic episodes, may have some pathophysiologic significance.
\end{abstract}

\section{Speculation}

Ketotic episodes with lethargy and severe hypotonia are another feature of glutaric aciduria due to glutaryl-CoA-dehydrogenase deficiency. During such episodes inhibition of the metabolism of branched-chain amino acids and fatty acids, secondary to the inability to metabolize glutaric acid, causes accumulation of branched short-chain monocarboxylic acids and of short- and medium-chain dicarboxylic acids.

Straight short- and medium-chain fatty acids influence the mitochondrial energy metabolism, and it is, therefore, speculated that the short-chain monocarboxylic acids, indicated in the present report to be accumulated in the mitochondria of the patient, contribute to the pathophysiology of the ketotic states.

Severe ketoacidotic episodes are a well known feature in a number of the organic acidurias. Patients with propionic, isovaleric, and methylmalonic acidurias are often subject to recurrent crises induced by high protein intake or by infections $(13,15,21)$. The clinical and biochemical presentations of these crises resemble one another closely: vomiting and lethargy followed by neurologic symptoms eventually leading to coma, and often to death. Besides the ketoacidosis, a pronounced lactic acidosis and lactic aciduria is seen in most cases. The present report, together with a recent report of Goodman et al. (7), indicates that glutaryl-CoA dehydrogenase deficiency (glutaric aciduria) may present ketotic episodes, similar to those of the other organic acidurias.

The patient described by Goodman et al. (7) died in a Reye's syndromelike state. Our patient has had two episodes of ketosis and lethargy. During these episodes, the urinary metabolic profiles of organic acids were studied in detail, in an attempt to elucidate the pathogenic mechanism leading to the severe clinical and biochemical symptoms.

\section{CASE REPORT}

The case history has been published elsewhere (9), as patient number 2. The patient (J.H.) was born 24th of June, 1971. He has the typical symptoms of glutaryl-CoA dehydrogenase deficiency (glutaric aciduria), namely: progressive dystonic cerebral palsy with universal hyperkinesias, including dystonic speech (2). Finally, he became totally helpless. He is apparently mentally normal.

The clinical symptoms during the two ketotic episodes were as follows: period 1 (21st-25th October, 1975): on the 21 st he started to vomit and passed a few loose stools, but there was no apparent change in the clinical state until the 23rd, when he had diarrhea and became lethargic with anorexia. There was no fever, but abundant sweat secretion. No special treatment was given and the patient was quite well again on the 25th. Period 2 (Ist-6th September, 1976): the patient was clinically well on the 1st of September, when he passed a loose stool. During the following days, he had diarrhea and occasionally vomited. On the $3 \mathrm{rd}$, he was febrile (temperature $38^{\circ} \mathrm{C}$ ) with hypercapnia, but infectious etiology was not established. He became increasingly hypotonic and on the 6th he was lethargic and difficult to contact. He recovered without treatment during the next days (27).

\section{METHODS}

Amino acids in urine and serum were measured with an automatic amino acid analyzer (3). Lactic and 3-OH-butyric acids in urine were determined by gas chromatography as trimethylsilylderivatives after extraction with ethylacetate (10). Measurement of glutaric and 3-OH-glutaric acids in urine was performed by means of gas chromatography after ion exchange and trimethylsilylation, as described by Thompson and Markey (24). Standard curves, measured with pimelic acid as the internal standard, were straight and through zero. The coefficients of variation, determined from nine double determinations of urine samples, were 6 and $7 \%$ for glutaric acid and 3-OH-glutaric acid, respectively. Urinary glutaconic, adipic, suberic, and sebacic acids were measured by selected ion monitoring (SIM) in ether-extracts, trimethylsilylated by means of BSTFA (bis-trimethyl-silyl-trifluoroacetamide)/1\% TMCS (trimethylchlorosilane). The gas chromatographic column was packed with $3 \%$ Dexsil 300 , and the ion- 
fragments used in the SIM analysis were in all cases, including the internal standard, diethylglutaric acid (DEGA), $\mathbf{M}^{+}-15$. The standard curves were straight in the range $0-60 \mu \mathrm{g} / \mathrm{mg}$ creatinine. The coefficients of variation, measured from 10 determinations, were for the dicarboxylic acids 3-8\%. The unconjugated volatile monocarboxylic acids in the urine were vacuum distillated according to Ando et al. (1) and determined by means of SIM. The gas chromatographic column was packed with Porapak PS, and the ion-fragments were: propionic acid 73, isobutyric acid 73, 2-Mebutyric acid 73 and 87 , isovaleric acid 87, and 4-pentenoic acid (internal standard) 100. The standard curves were straight and the coefficient of variation in the range $5-20 \mu \mathrm{g} / \mathrm{mg}$ creatinine was $10-22 \%$. Total volatile monocarboxylic acids were measured by the same method after hydrolysis with $\mathrm{Ba}(\mathrm{OH})_{2}$ as described by Tanaka (23). 2-oxo-acids were analysed as oxime derivatives (14), which were trimethylsilylated with BSTFA/1\% TMCS. The gas chromatographic column was packed with $3 \%$ Dexsil 300 , and the ion-fragments in the SIM analysis were: 2-oxo-butyric acid 246 $\mathrm{m} / \mathrm{e}, 2$-oxo-isovaleric acid $260 \mathrm{~m} / \mathrm{e}, 2$-oxo-3-Me-valeric acid 274 $\mathrm{m} / \mathrm{e}, 2$-oxo-iso-capronic acid $274 \mathrm{~m} / \mathrm{e}$, and 2-oxo-capronic acid (internal standard) $261 \mathrm{~m} / \mathrm{e}$. Standard curves were straight and through zero.

\section{RESULTS}

\section{ORGANIC ACIDS IN URINE}

Eleven urine samples were examined for a total number of 16 organic acids (Tables 1 and 2), including 2-oxo-butyric, 2-oxoisovaleric, 2-oxo-3-Me-valeric, and 2-oxo-isocapronic acids. Only the total sum of these oxo-acids are shown. 2-oxo-isovaleric and 2-oxo-3-Me-valeric acids contribute most to the total. During the $\mathrm{Ba}(\mathrm{OH})_{2}$ hydrolysis, used in the cleavage procedure for conjugates (23), these 2-oxo-acids may undergo oxidative decarboxylation to the corresponding saturated monocarboxylic acid. We have shown that aqueous solutions of approximately $75 \mu \mathrm{g}$ 2-oxo-acids/mg creatinine resulted in less than $7 \%$ degradation to the decarboxylated acids by the alkaline treatment. Another possible source of urinary short-chain monocarboxylic acids is from bacterial contamination of the urine samples. However, bacteria produce the unconjugated acids. This means that the volatile acids (Table 2) found after $\mathrm{Ba}(\mathrm{OH})_{2}$ hydrolysis are produced in the body. A last possibility for nonendogenous origin of these short-chain monocarboxylic acids is from the food. This source can, however, be excluded because diminished food intake was observed during the episodes and food composition was not changed. Therefore, it must be concluded that the volatile acids, especially those liberated by the alkaline treatment, are endogenous and originate from conjugates.
Four of the urine samples (underlined in the Tables) were collected during clinically affected periods. The excretion pattern of the organic acids in the ketotic periods was clearly different from that in the nonketotic periods (Tables 1 and 2, Figs. 1 and 2). Spot urines from the ketotic periods show that the excretions of the following acids were greatly enhanced: lactic acid, 3-OHbutyric acid, glutaconic acid, adipic acid, suberic acid, isobutyric acid, 2-Me-butyric acid, isovaleric acid, and the 2-oxo-acids. The excretion of glutaric and 3-OH-glutaric acids was moderately increased.

\section{AMINO ACIDS IN URINE}

Except for glycine the urinary excretion of amino acids was within control range in all the urine samples investigated. At one occasion (September 1, 1976) the urinary glycine excretion was $1400 \mu \mathrm{mole} / 24 \mathrm{hr}$ (controls $166-495 \mu \mathrm{mole} / 24 \mathrm{hr}$ (3)).

\section{DISCUSSION}

A primary defect in patients with the neurodegenerative metabolic disease glutaric aciduria, described by Goodman and coworkers $(6,7)$ and by us $(2,9)$, has been identified as an inability to metabolize glutaryl-CoA to crotonyl-CoA, most probably due to a deficiency of glutaryl-CoA dehydrogenase (Fig. 3). In order to distinguish this metabolic disorder from other conditions associated with excretion of glutaric acid (19), it should be named glutaryl-CoA dehydrogenase deficiency.

The present report and the case described by Goodman $e t$ al. (7) document that besides the progressive neurologic symptoms, acute episodes also occur. These episodes are characterized clinically by lethargy with hypotonia, and biochemically by enhanced urinary excretion of lactic, 3-OH-butyric, glutaric, 3-OH-glutaric, glutaconic, adipic, suberic, and 2-oxo-carboxylic acids together with conjugates of isobutyric, 2-Me-butyric, and isovaleric acids.

Besides the very large excretion of lactic and 3-OH-butyric acids, the substantial amounts of glutaconic acid in the urine samples taken during the attacks is the most striking feature (Table 1). It has been suggested $(7,9)$ that the biosynthesis of glutaconic acid (and 3-OH-glutaric acid) is catalyzed by the $\beta$-oxidation enzymes (Fig. 3). The enhanced accumulation and excretion of glutaconic acid in the ketotic episodes may be a reflection of a low affinity of glutaconyl-CoA towards the enoyl hydrases and an enhanced flow of ordinary $\beta$-oxidation intermediates. The excretion pattern of adipic, suberic, and sebacic acids is also remarkable. During the ketotic episodes, the excretion pattern of adipic and suberic acids resembles that in other ketotic patients (18). The most important biosynthetic pathway for these compounds, in these patients as well as in our patient, involves most probably

Table 1. Urinary excretion of nonvolatile organic acids $(\mu \mathrm{g} / \mathrm{mg}$ creatinine)

\begin{tabular}{|c|c|c|c|c|c|c|c|c|c|}
\hline & Lactic acid & $\begin{array}{l}\text { 3-OH-bu- } \\
\text { tyric acid }\end{array}$ & $\begin{array}{c}\text { Glutaric } \\
\text { acid }\end{array}$ & $\begin{array}{l}\text { 3-OH-glu- } \\
\text { taric acid }\end{array}$ & $\begin{array}{c}\text { Gluta- } \\
\text { conic acid }\end{array}$ & $\begin{array}{l}\text { Adipic } \\
\text { acid }\end{array}$ & $\begin{array}{c}\text { Suberic } \\
\text { acid }\end{array}$ & $\begin{array}{c}\text { Sebacic } \\
\text { acid }\end{array}$ & 2-oxo acid \\
\hline September 17, 1975 & 40 & 60 & 5300 & 350 & 42 & 17 & 2 & 38 & 9 \\
\hline October $21-22,1975$ & 25 & 45 & 600 & 230 & 14 & 24 & 2 & 65 & nd $^{\prime}$ \\
\hline October $22-23,1975$ & 400 & 2200 & 1700 & 370 & 89 & 100 & 13 & 28 & 8 \\
\hline October $23-24,1975^{2}$ & 800 & 4100 & 3100 & 530 & 280 & 224 & 32 & 1 & 29 \\
\hline October 24-25, 1975 & 1700 & 5500 & 3400 & 480 & 300 & 198 & 30 & 5 & 37 \\
\hline December $9-10,1975$ & 30 & 55 & 3800 & 300 & 42 & 19 & 2 & 4 & nd \\
\hline March 9-10, 1976 & 40 & 60 & 3800 & 330 & 14 & 17 & 2 & 48 & 12 \\
\hline September 1, 1976 & 95 & 45 & 100 & 350 & 58 & 21 & 5 & 3 & nd \\
\hline September 3,1976 & 2600 & 3000 & 5300 & 660 & 630 & 125 & 25 & 3 & 75 \\
\hline September 6, 1976 & 35 & 80 & 7900 & 460 & 93 & 74 & 16 & 0 & nd \\
\hline September $27-28,1976$ & 10 & 10 & 1900 & 290 & 30 & 24 & 4 & 6 & nd \\
\hline Control children $(n=5)$ & $9-32$ & $11-26$ & $\mathrm{ND}^{3}$ & ND & nd & $1-12$ & $0-3$ & $4-10$ & nd \\
\hline
\end{tabular}

'nd: not detectable, limit of detection approximately $1 \mu \mathrm{g} / \mathrm{mg}$ creatinine.

${ }^{2}$ On the dates underlined, the boy was clinically affected.

${ }^{3} \mathrm{ND}$ : not detectable, limit of detection approximately $10 \mu \mathrm{g} / \mathrm{mg}$ creatinine. 
Table 2. Urinary excretion of conjugated and free short-chain monocarboxylic acids ( $\mu \mathrm{g} / \mathrm{mg}$ creatinine)

\begin{tabular}{|c|c|c|c|c|}
\hline & $\begin{array}{c}\text { Propionic } \\
\text { acid }\end{array}$ & $\begin{array}{c}\text { Isobutyric } \\
\text { acid }\end{array}$ & $\begin{array}{c}\begin{array}{c}\text { 2-Me-butyric } \\
\text { acid }\end{array} \\
\end{array}$ & $\begin{array}{c}\text { Isovaleric } \\
\text { acid }\end{array}$ \\
\hline September 17,1975 & $8(6)^{1}$ & $4(\mathrm{nd})^{2}$ & 9(nd) & nd(nd) \\
\hline October $21-22,1975$ & $7(7)$ & 2(nd) & 2 (nd) & 2(nd) \\
\hline October $22-23,1975$ & 8 (nd) & 7 (nd) & 7 (nd) & 6(nd) \\
\hline October $23-24,1975$ & 5 (nd) & $10(1)$ & 15 (nd) & $8(n d)$ \\
\hline October 24-25, 1975 & 19(nd) & $15(5)$ & 34(nd) & 9(nd) \\
\hline$\overline{\text { December 9-10, } 1975}$ & 13 (nd) & $3($ nd) & nd(nd) & nd(nd) \\
\hline March 9-10, 1975 & $7(\mathrm{nd})$ & 2(nd) & $3(\mathrm{nd})$ & 2(nd) \\
\hline September 1, 1976 & $10($ nd) & $1(1)$ & $6(2)$ & nd(nd) \\
\hline September 3, 1976 & 6(nd) & $10(4)$ & $16(6)$ & $11(3)$ \\
\hline September 6, 1976 & S(nd) & $3(\mathrm{nd})$ & 4(nd) & 3(nd) \\
\hline Control & $8-16$ & $0-5$ & nd & $\begin{array}{l}\text { nd } \\
\text { (nd) }\end{array}$ \\
\hline Children $(n=5)$ & (nd) & (nd) & (nd) & (nd) \\
\hline
\end{tabular}

'The figures in the parentheses represent the free acids.

${ }^{2} \mathrm{nd}$, not detectable, limit of detection was approximately $1 \mu \mathrm{g} / \mathrm{mg}$ creatinine.

${ }^{3}$ On the dates underlined, the boy was clinically affected.

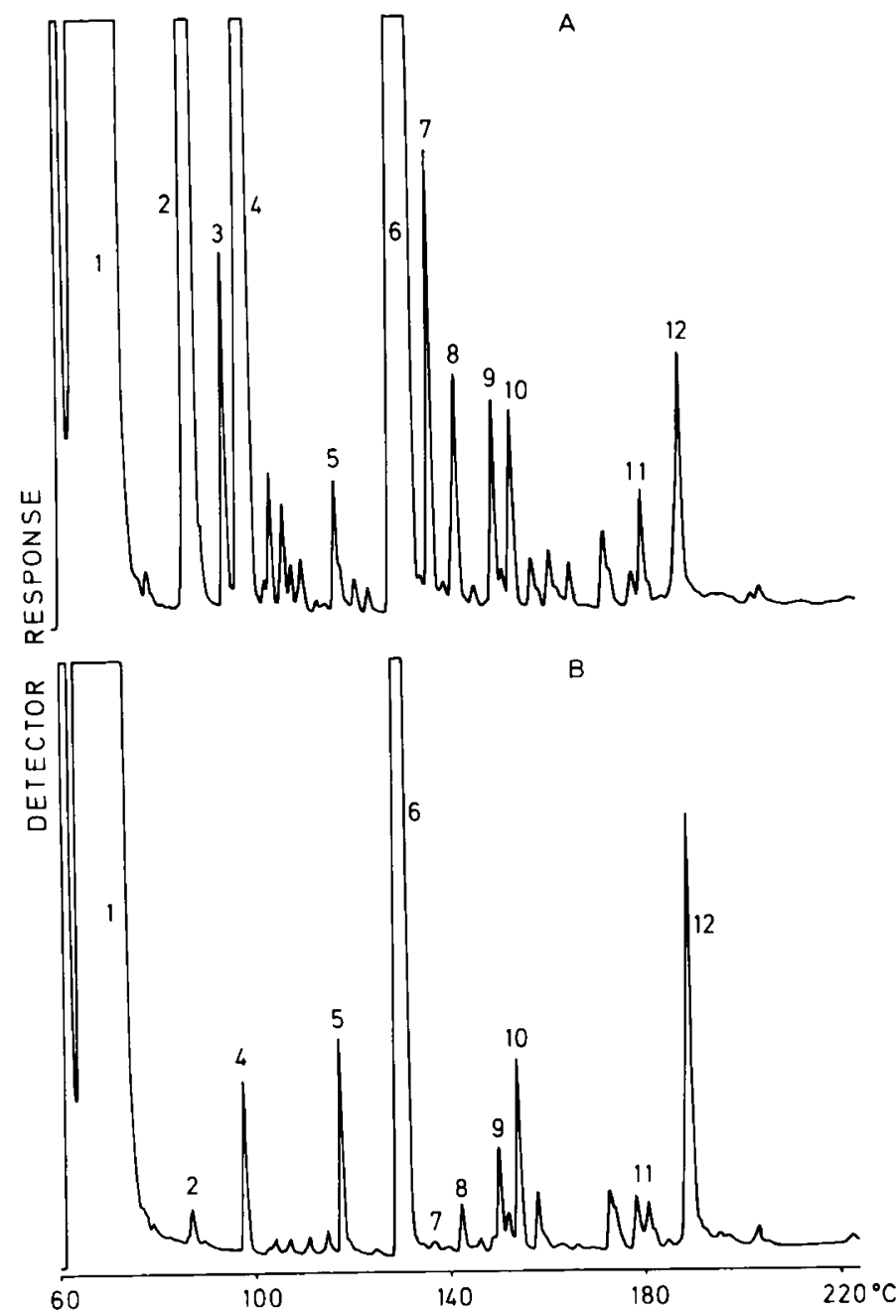

Fig. 1. Gas chromatograms (flameionisation detector response) of silylated extracts from the urine of the patient: $(A)$ during a ketotic attack (September 3, 1976) and $(B)$ between the attacks (March 9-10, 1976). The peaks are: 1) solvent, 2) lactic acid, 3) 2-OH-butyric acid, 4) 3-OH-butyric acid, 5) succinic acid, 6) glutaric acid, 7) glutaconic acid, 8) adipic acid, 9) 3-OH-glutaric acid, 10) diethylglutaric acid (int. std.), 11) citric acid, 12) hippuric acid. The GC column was a Dexsil 300 (3\%), temperature programmed from $60^{\circ} \mathrm{C}$ at $4^{\circ} \mathrm{C} / \mathrm{min}$. Injection and detection temperatures were $285^{\circ} \mathrm{C}$ and the helium flow-rate was $30 \mathrm{ml} / \mathrm{min}$.

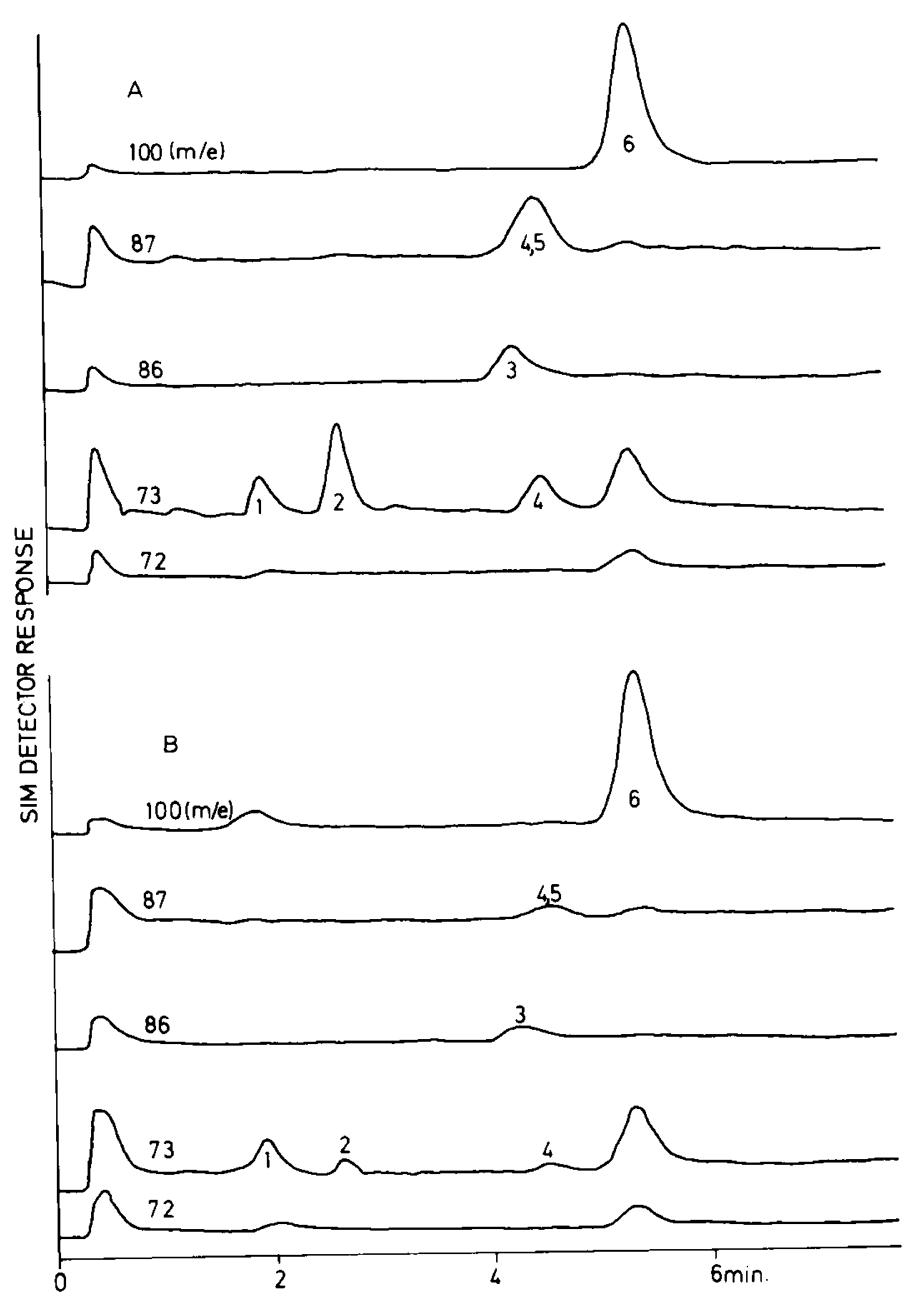

Fig. 2. Selected ion monitoring detector responses of hydrolysed and distilled urine samples from the patient: $(A)$ during a ketotic attack (September 3, 1976) and $(B)$ between the attacks (March 9-10, 1976). The peaks are: 1) propionic acid, 2) isobutyric acid, 3) crotonic acid, 4) 2-Mebutyric acid, 5) isovaleric acid, 6) 4-pentenoic acid (int.std.). The GC column was a Porapak PS column with an isothermal temperature at $190^{\circ} \mathrm{C}$. Injection temperature was $210^{\circ} \mathrm{C}$ and the helium carrier flow-rate was $40 \mathrm{ml} / \mathrm{min}$. The ionization was performed by electron impact at $70 \mathrm{ev}$ and the mass differentiation in a magnet field (AEI-MS-30). 


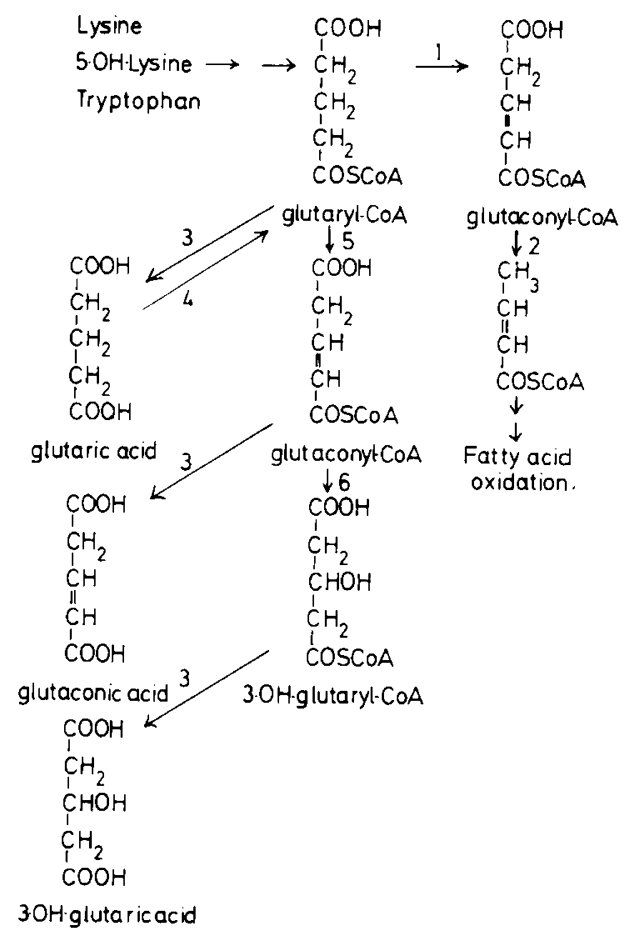

Fig. 3. The intermediate metabolism of glutaric acid and the postulated biosynthesis of glutaconic acid and 3-OH-glutaric acid. Reactions 1 and 2 are catalyzed by glutaryl-CoA dehydrogenase and glutaconyl-CoA decarboxylase. 3 may be acyl-CoA hydrolases and 4 acyl-CoA synthetases. 5 and 6 may be the $\beta$-oxidation enzymes acyl-CoA dehydrogenases and 2,3unsaturated acyl-CoA hydratases, respectively (see text).

oxidation of long-chain monocarboxylic acids, to long-chain dicarboxylic acids, followed by $\beta$-oxidation $(16,17)$. The occasional disproportionately increased excretion of sebacic acid (170975, 21$221075,22-231075$, and 9-100376) is not typical during ketotic states, but resembles more the pattern found in hypoglycin treated rats (22), where the $\beta$-oxidation is inhibited by methylenecyclopropylacetic acid, and in nonketotic dicarboxylic aciduria, where the $\beta$-oxidation seems to be inhibited (11). The biosynthetic mechanism for the formation of the dicarboxylic acids may be the same in these cases as in the ketotic states, but another mechanism may contribute. Ellin (4) has proposed another such mechanism, where the oxidation provides a detoxification pathway for accumulated medium-chain monocarboxylic acids. The moderately enhanced excretion of adipic acid in all the urines from the nonketotic periods may, therefore, also reflect an accumulation of hexanoyl-CoA, caused by a slight inhibition of the $\beta$-oxidation. The causal factor in this inhibition may be one or more compounds, accumulated as a result of the primary enzyme deficiency. The excretion of 3-OH-glutaric and glutaconic acids indicates that glutaric acid competes with fatty acids for the acyl-CoA dehydrogenases in the $\beta$-oxidation and may, therefore, exert an inhibitory effect.

The enhanced excretion of the 2-oxo-acids, which are intermediates in the metabolism of the branched-chain amino acids (Fig. 4), reflects most probably the well known increased catabolism of these amino acids during decreased food intake (5), and the excretion of the branched-chain monocarboxylic acids (predominantly as conjugates) indicates very strongly an inhibition of isobutyryl-, 2-Me-butyryl-, and isovaleryl-CoA dehydrogenases. Elucidation of the mechanism of this inhibition is in progress.

The report of Goodman et al. (7) described the final stage of their patient with glutaryl-CoA dehydrogenase deficiency as Reye's syndrome-like. The patient described in the present report was much less affected, but rather lethargic. Trauner et al. $(25,26)$ have proposed that the short-chain monocarboxylic acids, found in serum from patients with Reye's syndrome, are of pathophysi-

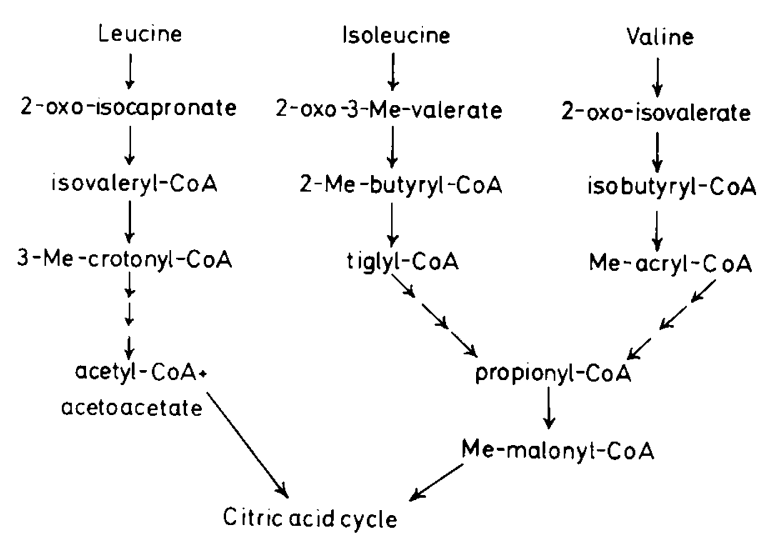

Fig. 4. The intermediate metabolism of the branched-chain amino acids, leucine, isoleucine, and valine.

ologic significance. It may, therefore, be speculated that the shortand medium-chain monocarboxylic acids, indicated to be accumulated in our patient, contribute to the clinical and biochemical symptoms of the ketotic episodes. Results from a systematic investigation of the effects of short-chain monocarboxylic acids on the energy metabolism of isolated rat liver mitochondria (8) show that isovaleric acid inhibits the oxidation of pyruvate and 2oxo-glutarate. Hexanoic acid that may be accumulated in the patient before detoxification to adipic acid, also inhibits the fatty acid oxidation $(8,12,20)$. If these acids are produced in the mitochondrion, in which they exert their effects, the concentration at the site of action may be toxic, even if the concentration in blood and urine is low.

\section{REFERENCES AND NOTES}

1. Ando, T., Rasmussen, K., Nyhan, W. L., and Donnell, G. N.: Propionic acidemia in patients with ketotic hyperglycinemia. J. Pediatr., 78: 827 (1971)

2. Brandt, N. J., Brandt, S., Christensen, E., Gregersen, N., and Rasmussen, K.: Glutaric aciduria in progressive choreoathetosis. Clin. Gen., 13: 77 (1978)

3. Brandt, N. J., Rasmussen, K., Brandt. S., Kølvraa, S., and Schønheyder, F.: D glyceric acidemia and non-ketotic hyperglycinemia. Acta Paediatr. Scand., 65 17 (1976)

4. Ellin, Å.: Fatty acid hydroxylation in rat kidney and liver microsomes. Thesis, Stockholm, 1977, p. 29.

5. Felig, P.: Amino acid metabolism in man. Ann. Rev. Biochem., 44: 933 (1975)

6. Goodman, S. I., Markey, S. P., Moe, P. G., Miles, B. S., and Teng, C. C.: Glutaric aciduria; a new disorder of amino acid metabolism. Biochem. Med., 12: 12 (1975)

7. Goodman, S. I., Norenberg, M. D., Shikes, R. H., Breslich, D. J., and Moe, P. G.: Glutaric aciduria, biochemical and morphologic considerations. J. Pediatr., 90: 746 (1977)

8. Gregersen, N.: Studies on the effect of saturated and unsaturated short-chain monocarboxylic acids on the energy metabolism of rat liver mitochondria. Pediat. Res. (in press).

9. Gregersen, N., Brandt, N. J., Christensen, E., Grøn, I., Rasmussen, K., and Brandt, S.: Glutaric aciduria, clinical and laboratory findings in two brothers. J. Pediatr., 90: 740 (1977)

10. Gregersen, N., Ingerslev, J., and Rasmussen, K.: Low molecular weight organic acids in the urine of the newborn. Acta Paediatr. Scand., 66: 85 (1977)

11. Gregersen, N., Lauritzen, R., and Rasmussen, K.: Suberylglycine excretion in the urine from a patient with dicarboxylic aciduria. Clin. Chim. Acta, 70: 417 (1976)

12. Hird, F. J. R. and Weidemann, M. J.: Oxidative phosphorylation accompanying oxidation of short-chain fatty acids by rat-liver mitochondria. Biochem. J., 98 : 378 (1966)

13. Hommes, F. A. and van den Berg, C. J. (eds): Inborn errors of metabolism (Academic Press, London, 1973)

14. Lancaster, G., Lamm, P., Scriver, C. R., Tjoa, S. S., and Mamer, O. A.: Quantitative analysis of branched-chain $\alpha$-keto acids as their trimethylsilylated oximes. Clin. Chim. Acta, 48: 279 (1973)

15. Nyhan, W. L. (ed.): Heritable disorders of amino acid metabolism, pattern of clinical expression and genetic variation. (John Wiley and Sons, New York, 1974)

16. Pettersen, J. E.: Formation of $n$-hexandioic acid from hexadecanoic acid by an initial $\omega$-oxidation in ketotic rats. Clin. Chim. Acta, 41:231 (1972)

17. Pettersen, J. E.: In vitro studies on the metabolism of hexadecanedioic acid and its mono-1-carnitine ester. Biochim. Biophys. Acta, 306: 1 (1973)

18. Pettersen, J. E., Jellum, E., and Eldjarn, L.: The occurrence of adipic and suberic acids in urine from ketotic patients. Clin. Chim. Acta, 38: 17 (1972)

19. Przyrembel, H., Wendel, U., Becker, K., Bremer, H. J., Bruinvis, L., Ketting, D., 
and Wadman. S. K.: Glutaric aciduria type II. Report on a previously undescribed metabolic disorder Clin. Chim. Acta, 66: 227 (1976)

20. Samson. F. E.. Dahl. N., and Dahl. D. R.: A study on the narcotic action of the short-chain fatty acids. J. Clin. Invest., 35: 1291 (1956)

21. Tanaka, K.: Disorders of organic acid metabolism. In: G. E. Grand: Biology of Brain Function. Vol. 3. p. 145 (New York. 1975)

22. Tanaka, K.: Isovaleric acidemia and its induction in experimental animal by hypoglycin-A. In: F. A. Hommes and C. J. van den Berg: Inborn Errors of Metabolism. (Academic Press, London, 1973)

23. Tanaka, K.: On the mode of action of hypoglycin A. J. Biol. Chem., 247: 7465 (1972)
24. Thompson, J. A., and Markey, S. P.: Quantitative metabolic profiling of urinary organic acids by gas chromatography-mass spectrometry: comparison of isolation methods. Anal. Chem., 47: 1313 (1975)

25. Trauner. D. A., Nyhan, W. L., and Sweetman, L.: Jamaican vomiting sickness and Reye's syndrome. N. Engl. J. Med., 295: 1481 (1977)

26. Trauner, D. A.. Nyhan, W. L., and Sweetman, L.: Short-chain organic acidemia and Reye's syndrome. Neurology, 25: 296 (1975)

27. Informed consent was obtained from the parents.

28. Received for publication June 6, 1978

29. Accepted for publication September 13, 1978 